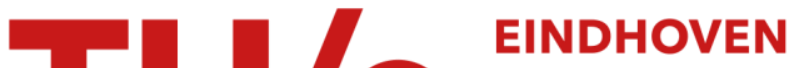 UNIVERSITY OF TECHNOLOGY
}

\section{Extensions to the context tree weighting method}

Citation for published version (APA):

Willems, F. M. J. (1994). Extensions to the context tree weighting method. In Proceedings of the 1994 IEEE International Symposium on Information Theory, 27 June - 1 July 1994, Trondheim, Norway (pp. 387-387). Institute of Electrical and Electronics Engineers. https://doi.org/10.1109/ISIT.1994.394632

DOI:

10.1109/ISIT.1994.394632

Document status and date:

Published: 01/01/1994

\section{Document Version:}

Publisher's PDF, also known as Version of Record (includes final page, issue and volume numbers)

\section{Please check the document version of this publication:}

- A submitted manuscript is the version of the article upon submission and before peer-review. There can be important differences between the submitted version and the official published version of record. People interested in the research are advised to contact the author for the final version of the publication, or visit the $\mathrm{DOI}$ to the publisher's website.

- The final author version and the galley proof are versions of the publication after peer review.

- The final published version features the final layout of the paper including the volume, issue and page numbers.

Link to publication

\section{General rights}

Copyright and moral rights for the publications made accessible in the public portal are retained by the authors and/or other copyright owners and it is a condition of accessing publications that users recognise and abide by the legal requirements associated with these rights.

- Users may download and print one copy of any publication from the public portal for the purpose of private study or research.

- You may not further distribute the material or use it for any profit-making activity or commercial gain

- You may freely distribute the URL identifying the publication in the public portal.

If the publication is distributed under the terms of Article 25fa of the Dutch Copyright Act, indicated by the "Taverne" license above, please follow below link for the End User Agreement:

www.tue.nl/taverne

Take down policy

If you believe that this document breaches copyright please contact us at:

openaccess@tue.nl

providing details and we will investigate your claim. 


\title{
Extensions to the Context Tree Weighting Method
}

\author{
Frans M.J. Willems \\ Eindhoven Univ. of Technology, Electrical Engineering Dept., P.O. Box 513, 5600 MB Eindhoven, The Netherlands
}

Abstract - We modify the basic context tree weighting method so that past symbols are not needed, and that the context tree depth is infinite. For stationary ergodic sources we now achieve entropy.

\section{Introduction}

The context tree weighting method [2] was first presented at the previous IEEE ISIT in San Antonio, Texas. It appears to be an efficient implementation for weighting all the coding distributions (universal over the parameters) corresponding to FSMX models, whose maximum depth does not exceed $d$. An FSMX model is determined by a proper and complete set $\mathcal{S}$ of postfixes. Together these postfixes form a tree that grows towards $-\infty$. Each sequence $\cdots x_{t-2} x_{t-1}$ has a unique postfix in $S$, i.e. it passes through a unique leaf in the corresponding tree. This postfix (leaf) determines the probability that $x_{t}$, i.e. the next symbol generated by the (binary) source, is a 1 .

The analysis of this weighting method turns out to be very straightforward (see [3]). It shows that the performance is as good as we can possibly hope, not only asymptotically but also for finite sequence lengths. Here we will propose two extensions to the basic weighting method.

II. Coding without knowledge of past symbols In its basic form the context tree weighting method needs for every processed symbol $x_{t}$ for $t=1,2, \cdots, T$, its context $x_{t-d} x_{t-d+1} \cdots x_{t-1}$, where $d$ is the depth of the context tree. This implies that for processing $x_{1}$ we must have access to $x_{1-d}, x_{2-d}, \cdots, x_{0}$. If this is not the case, the straightforward way is to start processing only after having seen a full context, i.e. to start processing with $x_{d+1}$. The first context $x_{1} x_{2} \cdots x_{d}$ is sent to the decoder in an uncoded way, requiring $d$ bits.

In the ideal situation where we do know the model $\mathcal{S}$, we could send a symbol $x_{t}$ in an uncoded way, if its context $x_{1} x_{2} \cdots x_{t-1}$ does not have a postfix in $S$. The number of uncoded symbols $\Delta_{S}\left(x_{1}^{T}\right)$ now depends on the postfix set $S$ and on the actual sequence $x_{1}^{T}$, thus not knowing the past costs $\Delta_{S}\left(x_{1}^{T}\right)$ bits, if we do know $S$. Note that $\Delta_{S}\left(x_{1}^{T}\right) \leq d$ for models $\mathcal{S}$ that fit into a context tree of depth $d$.

Our first result is now that, also in the case where we do not know the model $\mathcal{S}$, we loose not more than $\Delta_{S}\left(x_{1}^{T}\right)$ bits, if we do not have access to the past. In other words the starting redundancy is not more than $\Delta_{S}\left(x_{1}^{T}\right)$. This is demonstrated by modifying the context tree weighting method. The key idea is to assume that the symbols $x_{1-d}, x_{2-d}, \cdots, x_{0}$ all have value $\varepsilon$, and to consider a ternary context tree in which weighted probabilities are updated as usual, the difference being that now every node in principle has three children.

III. Infinite depth context tree methods

A second unpleasant property of the basic context tree weighting method is that the depth $d$ of the context tree is finite. Only for models that fit into this finite context tree, the weighting method achieves its desirable redundancy bounds.

Our second result is that we can generalize the basic context tree weighting method to the situation where the context tree depth is infinite, and still achieve a storage complexity which is not larger than linear in the sequence length $T$. The firs observation that leads to this result is that we have $T$ contexts each starting (ending) with a (semi-infinite) sequence of $\varepsilon$ 's which therefore all differ from each other. The second observation is that the context tree need only contain non-unique nodes that split, or nodes that are unique with a non-unique parent (a node is said to be unique if the subsequence to which it corresponds does only occur once in $\cdots \epsilon \epsilon x_{1} x_{2} \cdots x_{T}$, a node splits if it has more than one child).

It can now be shown that our modified context tree does not contain more than $T$ (internal) nodes. For processing $x_{t}$ it is however necessary that the sequence $x_{1} x_{2} \cdots x_{t-1}$ is available in memory. This results in a total storage complexity not larger than linear in $T$. Note that this relates to the concept DAWG proposed by Blumer et al. [1]

The performance is as expected, the model redundancy being upperbounded by $2|\mathcal{S}|-1$ bits, now for all $S$.

\section{Achieving entropy for arbitrary stationary} ergodic sources

Now that we can use the context tree weighting algorithm without knowing past symbols and for infinite depth context trees, we can show that this method achieves entropy for arbitrary stationary and ergodic sources. Let $c\left(x_{1}^{T}, \mathcal{S}\right)=$ $\frac{|S|}{2} \log _{2} \frac{T}{|\mathcal{S}|}+|\mathcal{S}|+2|\mathcal{S}|-1+\Delta_{S}\left(x_{1}^{T}\right)+2$, i.e. the upper bound for the total parameter, model, starting and coding redundancy for large $T$. Take $\mathcal{S}=\{0,1\}^{d}$ for arbitrary $d$, then

$$
\begin{aligned}
L\left(x_{1}^{T}\right) & \leq \sum_{s \in S}\left(a_{s} \log _{2} \frac{a_{s}+b_{s}}{a_{s}}+b_{s} \log _{2} \frac{a_{s}+b_{s}}{b_{s}}\right)+c\left(x_{1}^{T}, S\right) \\
& \leq \sum_{s \in S}\left(a_{s} \log _{2} \frac{1}{1-\pi_{s}}+b_{s} \log _{2} \frac{1}{\pi_{s}}\right)+c\left(x_{1}^{T}, \mathcal{S}\right),
\end{aligned}
$$

where $a_{s}$ and $b_{s}$ are the number of occurences of $s 0$ resp $s 1$ in $x_{1}^{T}$, and $\pi_{s}=P_{a}\left(X_{d+1}=1 \mid X_{1}^{d}=s\right)$, i.e. the actual probability for $s \in S$. Using the ergodic theorem we obtain (entropy in bits) that

$$
L\left(x_{1}^{T}\right) / T \leq H\left(X_{d+1} \mid X_{1} \cdots X_{d}\right) \text { with probability } 1
$$

for $T \rightarrow \infty$ for all $d$. Since $\lim _{d \rightarrow \infty} H\left(X_{d+1} \mid X_{1} \cdots X_{d}\right)=$ $H_{\infty}(X)$ it follows, that for stationary ergodic sources the codeword-length $L\left(x_{1}^{T}\right)$ divided by the sequence length is, with probability one, not larger than the entropy of the source.

[1] A. Blumer, References ner, A. Ehrenfeucht, D. Haussler, and R. Bear Size Finite Automata for the Set of All Sub( Eur. A ssoc. Theoret. Camput. Sci., vol. 21, pp. 12-20, 1983

[2] F.M.J. Willems, Y.M. Shtarkov and Tj.J. Tjalkens, "Context Tree Weighting : A Sequential Universal Source Coding Procedure for FSMX Sources," IEEE Int. Symp. Inform. Theory, San Antonio, Texas, January 17-22, 1993, p. 59.

[3] F.M.J. Willems, Y.M. Shtarkov and Tj.J. Tjalkens, "The Context Tree Weighting Method : Basic Properties," submitted to the IEEE Trans. Inform. Theory, July 1993 